\title{
B4C thin films for neutron detection
}

\author{
Carina Höglund, Jens Birch, Ken Andersen, Thierry Bigault, Jean-Claude Buffet, \\ Jonathan Correa, Patrick van Esch, Bruno Guerard, Richard Hall-Wilton, Jens Jensen, \\ Anton Khaplanov, Francesco Piscitelli, Christian Vettier, \\ Wilhelmus Vollenberg and Lars Hultman
}

\section{Linköping University Post Print}

N.B.: When citing this work, cite the original article.

Original Publication:

Carina Höglund, Jens Birch, Ken Andersen, Thierry Bigault, Jean-Claude Buffet, Jonathan Correa, Patrick van Esch, Bruno Guerard, Richard Hall-Wilton, Jens Jensen, Anton Khaplanov, Francesco Piscitelli, Christian Vettier, Wilhelmus Vollenberg and Lars Hultman, B4C thin films for neutron detection, 2012, Journal of Applied Physics, (111), 10, 104908. http://dx.doi.org/10.1063/1.4718573

Copyright: American Institute of Physics (AIP) http://www.aip.org/

Postprint available at: Linköping University Electronic Press http://urn.kb.se/resolve?urn=urn:nbn:se:liu:diva-79823 


\title{
$\mathrm{B}_{\mathbf{4}} \mathrm{C}$ thin films for neutron detection
}

\author{
Carina Höglund, ${ }^{1,2, a)}$ Jens Birch, ${ }^{2}$ Ken Andersen, ${ }^{1}$ Thierry Bigault, ${ }^{3}$ Jean-Claude Buffet, ${ }^{3}$ \\ Jonathan Correa, ${ }^{3}$ Patrick van Esch, ${ }^{3}$ Bruno Guerard, ${ }^{3}$ Richard Hall-Wilton, ${ }^{1}$ Jens Jensen, ${ }^{2}$ \\ Anton Khaplanov, ${ }^{1,3}$ Francesco Piscitelli, ${ }^{3}$ Christian Vettier, ${ }^{1,4}$ Wilhelmus Vollenberg, ${ }^{5}$ \\ and Lars Hultman ${ }^{2}$ \\ ${ }^{1}$ European Spallation Source ESS AB, P.O. Box 176, SE-221 00 Lund, Sweden \\ ${ }^{2}$ Department of Physics, Chemistry and Biology (IFM), Thin Film Physics Division, Linköping University, \\ SE-581 83 Linköping, Sweden \\ ${ }^{3}$ Institute Laue Langevin, Rue Jules Horowitz, FR-380 00 Grenoble, France \\ ${ }^{4}$ European Synchrotron Radiation Facility, BP 220, FR-380 43 Grenoble Cedex 9, France \\ ${ }^{5}$ Vacuum, Surfaces and Coatings Group (TE/VSC), CERN, CH-1211 Geneva 23, Switzerland
}

(Received 22 February 2012; accepted 20 April 2012; published online 23 May 2012)

\begin{abstract}
Due to the very limited availability of ${ }^{3} \mathrm{He}$, new kinds of neutron detectors, not based on ${ }^{3} \mathrm{He}$, are urgently needed. Here, we present a method to produce thin films of ${ }^{10} \mathrm{~B}_{4} \mathrm{C}$, with maximized detection efficiency, intended to be part of a new generation of large area neutron detectors. $\mathrm{B}_{4} \mathrm{C}$ thin films have been deposited onto Al-blade and $\mathrm{Si}$ wafer substrates by dc magnetron sputtering from ${ }^{\text {nat }} \mathrm{B}_{4} \mathrm{C}$ and ${ }^{10} \mathrm{~B}_{4} \mathrm{C}$ targets in an Ar discharge, using an industrial deposition system. The films were characterized with scanning electron microscopy, elastic recoil detection analysis, x-ray reflectivity, and neutron radiography. We show that the film-substrate adhesion and film purity are improved by increased substrate temperature and deposition rate. A deposition rate of $3.8 \AA / \mathrm{s}$ and substrate temperature of $400{ }^{\circ} \mathrm{C}$ result in films with a density close to bulk values and good adhesion to film thickness above $3 \mu \mathrm{m}$. Boron-10 contents of almost 80 at. $\%$ are obtained in $6.3 \mathrm{~m}^{2}$ of $1 \mu \mathrm{m}$ thick ${ }^{10} \mathrm{~B}_{4} \mathrm{C}$ thin films coated on Al-blades. Initial neutron absorption measurements agree with Monte Carlo simulations and show that the layer thickness, number of layers, neutron wavelength, and amount of impurities are determining factors. The study also shows the importance of having uniform layer thicknesses over large areas, which for a full-scale detector could be in total $\sim 1000 \mathrm{~m}^{2}$ of two-side coated Al-blades with $\sim 1 \mu \mathrm{m}$ thick ${ }^{10} \mathrm{~B}_{4} \mathrm{C}$ films. (C) 2012 American Institute of Physics. [http://dx.doi.org/10.1063/1.4718573]
\end{abstract}

\section{INTRODUCTION}

In the last few years, the demands for ${ }^{3} \mathrm{He}$ have increased, mainly due to U.S. Homeland Security programs, which in the past five years have used $85 \%$ of the U.S. supply. ${ }^{1}$ After the end of the Cold War, the production of this rare gas is very limited due to the main source being the radioactive decay of tritium. ${ }^{2}$ This has lead to unaffordable prices, especially for users outside the U.S., ${ }^{3}$ and an urgent need for alternatives to ${ }^{3} \mathrm{He}$-based neutron detectors for large-scale neutron research facilities. ${ }^{1-5}$ The need is especially important for new large area neutron detectors, which until 2015 will require more than the complete U.S. supply of ${ }^{3} \mathrm{He} .^{1,3}$

One possible replacement for ${ }^{3} \mathrm{He}$ for neutron detection is the boron isotope ${ }^{10} \mathrm{~B} .{ }^{10} \mathrm{~B}$ has a relatively high neutron absorption cross section, resulting in an absorption efficiency of $70 \%$ compared to ${ }^{3} \mathrm{He}$, at a neutron wavelength of $1.8 \AA$. Naturally occurring boron contains $20 \%$ of ${ }^{10} \mathrm{~B}$, but due to the almost $10 \%$ mass difference to the other boron isotope, ${ }^{11} \mathrm{~B}$, the isotope separation is relatively easy.

${ }^{10} \mathrm{~B}$ has been chosen as a possible absorbing element in a new generation of neutron detectors. We are planning to build a demonstrator for a large area neutron detector with the

\footnotetext{
a) Author to whom correspondence should be addressed. Electronic mail: carina.hoglund@esss.se. Telephone:+46721792023.
}

IN5 gas detector at the Institute Laue Langevin (ILL) as a benchmark. ${ }^{6}$ The detector will contain Al-blades that are coated with ${ }^{10} \mathrm{~B}_{4} \mathrm{C}$ layers where ${ }^{10} \mathrm{~B}$ absorbs the incident neutrons. With $94 \%$ probability, the nuclear reaction is ${ }^{10} \mathrm{~B}+\mathrm{n}$ $\rightarrow{ }^{7} \mathrm{Li}(0.84 \mathrm{MeV})+{ }^{4} \mathrm{He}(1.47 \mathrm{MeV})+\gamma(0.48 \mathrm{MeV})$ and with $6 \%$ probability, it is ${ }^{10} \mathrm{~B}+\mathrm{n} \rightarrow{ }^{7} \mathrm{Li}(1.02 \mathrm{MeV})+{ }^{4} \mathrm{He}$ $(1.78 \mathrm{MeV})$. Both the ${ }^{7} \mathrm{Li}$ and ${ }^{4} \mathrm{He}$ isotopes can be detected, with both temporal and spatial resolutions, in a detecting gas. Due to a reduced escape probability for the reaction particles with increasing depth of the events, the intended detector will be based on a number of consecutive blades, coated with thin

${ }^{10} \mathrm{~B}$-containing films, to be traversed by the neutrons. ${ }^{7,8} \mathrm{~A}$ full-scale area detector, for an IN5-like instrument, is supposed to have an active surface of $\sim 30 \mathrm{~m}^{2}$, which corresponds to $\sim 1000 \mathrm{~m}^{2}$ of ${ }^{10} \mathrm{~B}$-containing thin films.

For such a neutron detector to be competitive to the ${ }^{3} \mathrm{He}$ based detectors used today, high-quality neutron converting thin films are important ingredients. The neutron detection efficiency has to be maximized, meaning that the thin film must contain a maximum amount of the neutron absorbing element ${ }^{10} \mathrm{~B}$ and a minimum of unfavorable impurities like $\mathrm{H}, \mathrm{C}, \mathrm{N}$, and $\mathrm{O}$. The films should have a uniform thickness over large areas. The film's density determines the optimal thickness because it affects both the neutron absorption efficiency and reaction particle range. To achieve a long time functioning detector, the thin films must as well have good 
adhesion to the substrates and reduced aging effects under operational conditions. Moreover, for a full-scale large area neutron detector, the thin film process needs to be scalable for several hundred square meters of two-sided coated substrates. Finally, all these requirements have to be fulfilled at an affordable price.

${ }^{10} \mathrm{~B}_{4} \mathrm{C}$ was chosen as the thin film material instead of pure ${ }^{10} \mathrm{~B}$ because it is easy to handle in a deposition process like dc magnetron sputtering. ${ }^{\text {nat }} \mathrm{B}_{4} \mathrm{C}$ is also well known to have excellent wear resistance, and thermal and chemical stability. ${ }^{9}$ Several papers report about the growth of ${ }^{\text {nat }} \mathrm{B}_{4} \mathrm{C}$ thin films using either rf or dc magnetron sputtering. ${ }^{9-13}$ The majority of these films are intended for very hard coatings applications, meaning that the main focus is to find ways to maximize the hardness. ${ }^{13,14}$ Unfortunately, the high hardness is often related to bad substrate adhesion for film thicknesses in the micrometer range, ${ }^{15}$ mainly due to high amounts of residual stresses in ${ }^{\text {nat }} \mathrm{B}_{4} \mathrm{C}$ thin films. ${ }^{10,16-18}$ Despite this, the possibility to grow over $50 \mu \mathrm{m}$ thick adherent ${ }^{\text {nat }} \mathrm{B}_{4} \mathrm{C}$ coatings with rf sputtering is reported. ${ }^{12}$ There are yet no publications about the process development of boron-10 enriched ${ }^{10} \mathrm{~B}_{4} \mathrm{C}$ thin films.

This paper concentrates on the ${ }^{10} \mathrm{~B}_{4} \mathrm{C}$ thin film development intended to be a part of the first prototype for a new large area neutron detector. We combine Monte Carlo simulations and experiments to reveal the optimum thin films, and use neutron radiography as an initial characterization method for the films' neutron absorption ability. While the simulations have been implemented with ${ }^{10} \mathrm{~B}_{4} \mathrm{C}$, the experimental work has been carried out using both ${ }^{10} \mathrm{~B}_{4} \mathrm{C}$ and ${ }^{\text {nat }} \mathrm{B}_{4} \mathrm{C}$ sputter targets, mainly due to the high cost of boron10 enriched material. ${ }^{7}$

To start with, the detector design and some key parameters for the thin films were simulated, with the aim to maximize the neutron detection efficiency of the detector for applied deposition parameters. It was important to predict the optimal film thicknesses, desired number of layers, and how different film contaminants affect the detection efficiency. Based on the results from the simulations, we have investigated a process for growth of $\mathrm{B}_{4} \mathrm{C}$ thin films using $\mathrm{dc}$ magnetron sputtering in an industrial deposition system. This deposition technique was chosen because it can be relatively easily up-scaled, incorporates little impurities, does not require very high deposition temperatures, and allows for high deposition rates. Here, we report the feasibility of magnetron sputter deposited ${ }^{10} \mathrm{~B}_{4} \mathrm{C}$ thin films for neutron detectors by studying density, adhesion, amount of impurities, thickness uniformity, and neutron absorption as a function of deposition parameters such as deposition time, temperature, number of sputtering sources, and applied power.

\section{EXPERIMENTAL}

\section{A. Thin films}

Deposition experiments were performed at Linköping University in an industrial CC800/9 deposition system manufactured by CemeCon AG in Germany at a base pressure of $2.5 \times 10^{-4} \mathrm{~Pa}$. Up to four $88 \times 500 \times 5 \mathrm{~mm}^{3}{ }^{\text {nat }} \mathrm{B}_{4} \mathrm{C}$ and ${ }^{10} \mathrm{~B}_{4} \mathrm{C}$ (>95\% enriched) sputtering targets made by chemically identical methods by RHP-Technology GmbH \& Co. $\mathrm{KG}$, bonded to a $\mathrm{Cu}$-plate, were used to grow up to $3 \mu \mathrm{m}$ thick $\mathrm{B}_{4} \mathrm{C}$ films.

Rolled Al-blades, $0.5 \mathrm{~mm}$ thick, from the alloy EN AW5083 were used as substrate material, to comply with the demonstrator specifications, while single crystal $\mathrm{Si}(001)$ wafers were used for analyses, which require a smooth substrate surface. Prior to deposition, the substrates were cleaned in ultrasonic baths of Neutracon followed by deionized water, or acetone followed by 2-propanol, for $\mathrm{Al}$ and $\mathrm{Si}$, respectively. All substrates were blown dry in dry $\mathrm{N}_{2}$.

Up to 24 Al-blades $(20 \times 180 \mathrm{~mm}$ in size $)$ were mounted onto a sample carousel, which allows for 2-axis planetary rotation and 2-sided depositions. The $\mathrm{Si}$ pieces were mounted by attaching them to the Al-blades. Prior to deposition, the deposition system was evacuated at full pumping speed for $3 \mathrm{~h}$ and the substrates degassed at temperatures up to $500^{\circ} \mathrm{C}$. During deposition, the Ar partial pressure was kept at $\sim 0.8 \mathrm{~Pa}$. The $\mathrm{B}_{4} \mathrm{C}$ magnetrons were operated in $\mathrm{dc}$ mode and the maximum applied power was $4000 \mathrm{~W}$ to each magnetron.

Isotope-specific compositional analysis was performed with time-of-flight elastic recoil detection analysis (ToFERDA), using a $31.5 \mathrm{MeV}^{127} \mathrm{I}^{9+}$ beam at $66^{\circ}$ incidence and $45^{\circ}$ recoil scattering angle. The recoil energy of each element was converted to relative elemental depth profiles using the conTES code. ${ }^{19}$ Scanning electron microscopy (SEM) was carried out using a LEO 1550 instrument, equipped with an in-lens detector operated at $5 \mathrm{kV}$ at a working distance of $4 \mathrm{~mm}$.

The film densities were determined by $\mathrm{Cu}-\mathrm{K} \alpha_{1}$ x-ray reflectivity using a Philips X'Pert MRD diffractometer, operated with a parabolic multilayer mirror followed by a $2 \times \mathrm{Ge}(220)$ monochromator crystal on the primary side, and an asymmetric $2 \times \mathrm{Ge}(220)$ triple-axis collimator crystal.

\section{B. Simulations}

As a coupling between the experimental results when operating a prototype detector based on ${ }^{10} \mathrm{~B}_{4} \mathrm{C}$ films and the measured $\mathrm{B}_{4} \mathrm{C}$ thin film parameters, a Monte Carlo simulation program has been developed. Previous simulations were concerned with boron-10 enriched boron layers ${ }^{20}$ or optimizing the single parameter of layer thickness without including other parameters, such as the number of layers, ${ }^{21}$ which leads to a significant underestimate in the maximum obtainable efficiency. Our software also models the passage of a neutron beam through an array of Al-blades supporting ${ }^{10} \mathrm{~B}_{4} \mathrm{C}$ films, placed orthogonally to the incident neutron beam. Both possible reaction paths are included in the simulation. The resulting detector efficiency can be predicted not only depending on the neutron wavelength, but also depending on the number of ${ }^{10} \mathrm{~B}_{4} \mathrm{C}$ layers, their thickness, density, and composition.

When a beam of neutrons passes through the detector, the neutron capture cross-section of ${ }^{10} \mathrm{~B}$ is used to predict the interaction probability as a function of layer number as well as the depth of the neutron conversion within each layer. At this point, the exact conversion location of the neutron 
within the detector is given. The two reaction particles resulting from a conversion $\left({ }^{7} \mathrm{Li}\right.$ and $\left.{ }^{4} \mathrm{He}\right)$ are emitted backto-back. Their direction is randomized uniformly. Typically one of the particles is absorbed in the Al-blade, while the other escapes into the detecting gas. A simulation using the SRIM software package ${ }^{22}$ was used in order to generate a distribution of ${ }^{7} \mathrm{Li}$ and ${ }^{4} \mathrm{He}$ ranges and energy losses as they leave the ${ }^{10} \mathrm{~B}_{4} \mathrm{C}$ film and traverse the gas volume, taking into account the effect of any contaminants within the film. Here, a detection threshold for a realistic detector is applied to the energy deposited in the gas, resulting in a prediction of whether a given neutron gives rise to a detector signal or not. The detector efficiency is simply the number of detections normalized to the number of simulated neutrons. ${ }^{23}$

\section{Neutron radiography}

A radiological method was used as verification of the neutron absorption (and ${ }^{10} \mathrm{~B}$-content in addition to the ToFERDA measurements) in thin films produced under various conditions. A neutron imaging detector where neutrons are converted in a ${ }^{3} \mathrm{He}$ gas volume, BIDIM $26,{ }^{24}$ was used to measure this. The conversion position is determined using a 2-dimensional multi-wire readout with 128 channels in each direction and a 2-mm wire pitch. The result is a $256 \times 256 \mathrm{~mm}$ image with a pixel size of $2 \times 2 \mathrm{~mm}$.

Aluminum blades coated with ${ }^{\text {nat }} \mathrm{B}_{4} \mathrm{C}$ layers were placed adjacent to the window of the detector and illuminated by a neutron beam with a dominating wavelength of $2.5 \AA$. A reference measurement without blades was also performed. A combination of these two measurements was used to determine the intensity in each pixel, which tells where each neutron was lost due to absorption in the ${ }^{\text {nat }} \mathrm{B}_{4} \mathrm{C}$ layers. Conveniently, this method allowed several coated blades to be characterized in a single measurement, reducing the impact of systematic fluctuation. Furthermore, the spatial resolution of the detector allows profiling the ${ }^{10} \mathrm{~B}$-density along the length of the blade.

\section{RESULTS AND DISCUSSION}

\section{A. Simulations}

Detection efficiency simulations versus different layer parameters are shown in Fig. 1. The calculations were performed for boron-10 enriched ${ }^{10} \mathrm{~B}_{4} \mathrm{C}$, meaning that 80 atomic (at.) $\%$ of the material is ${ }^{10} \mathrm{~B}$. All simulations assume the material to have the same density as bulk $\mathrm{B}_{4} \mathrm{C}$, which is not usually achievable experimentally and, if necessary, has to be taken into account separately. We hereby define the conversion efficiency to be the probability for a neutron to be converted to ${ }^{7} \mathrm{Li}$ and ${ }^{4} \mathrm{He}$, while the escape efficiency is this conversion efficiency multiplied by the probability for one of these reaction particles to escape from the layer to the detecting gas. For the simulations in Figs. 1(a), 1(b), and 1(d), the neutron wavelength was chosen to be $4.5 \AA$, which is a typical wavelength used at the IN5 at the ILL.

The conversion efficiency in Fig. 1(a) is almost 100\% for film thicknesses above $2 \mu \mathrm{m}$, when assuming a detector design with 30 layers. However, the escape efficiency of the
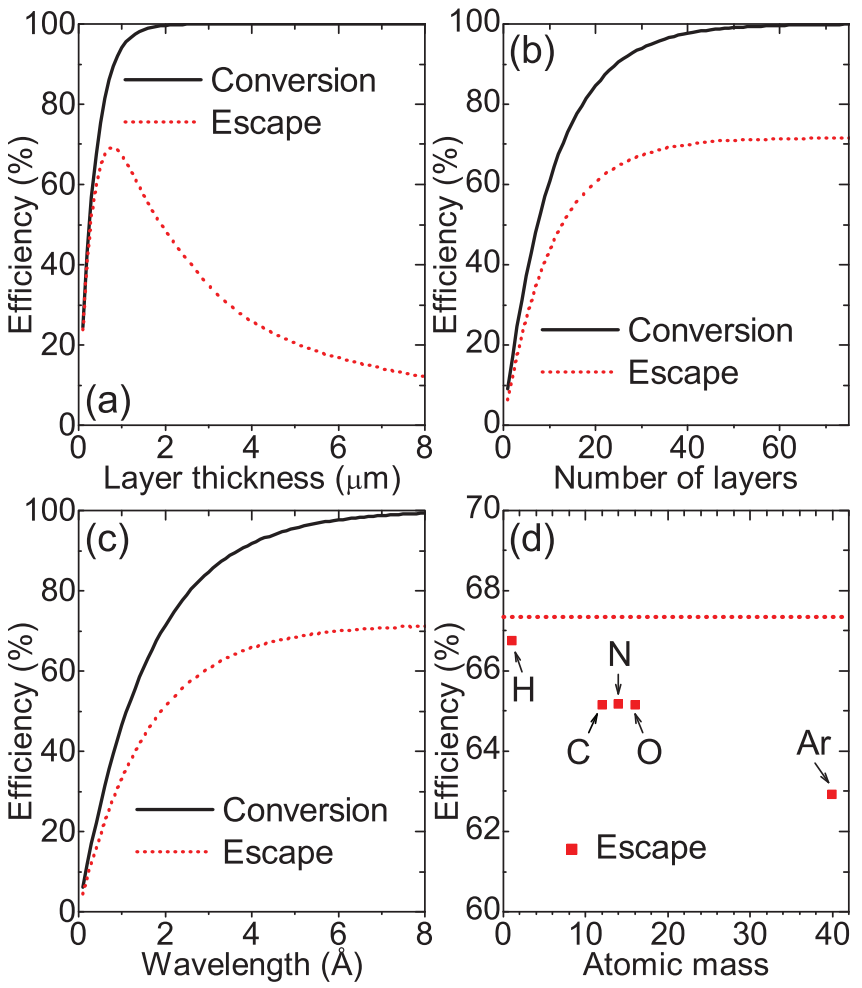

FIG. 1. Simulated parameters for optimal ${ }^{10} \mathrm{~B}_{4} \mathrm{C}$ thin film parameters to maximize the neutron detection efficiency, showing the effect of (a) layer thickness for 30 layers, (b) varied number of layers for $1 \mu \mathrm{m}$ layer thickness, (c) changing the neutron wavelength for 30 layers of $1 \mu \mathrm{m}$ thickness, and (d) adding 10 at. \% of typical contaminants to 30 layers of $1 \mu \mathrm{m}$ thickness and the red dotted line corresponding to no contaminants. The neutron wavelength in (a), (b), and (d) is chosen to be $4.5 \AA$.

reaction particles decreases rapidly already at film thicknesses above $1 \mu \mathrm{m}$. The average ranges at which the reaction particles loose all energy, as calculated by SRIM, ${ }^{22}$ are the following: $\alpha(1.47 \mathrm{MeV})=3.4 \mu \mathrm{m}, \alpha(1.78 \mathrm{MeV})=4.3 \mu \mathrm{m},{ }^{7} \mathrm{Li}$ $(0.84 \mathrm{MeV})=1.7 \mu \mathrm{m}$, and ${ }^{7} \mathrm{Li}(1.02 \mathrm{MeV})=1.9 \mu \mathrm{m}$. The theoretical maximum escape efficiency of $69 \%$ is obtained for a film thickness of $800 \mathrm{~nm}$. This simulation shows the importance of having good control over the film thickness and its reproducibility. It also reveals that it is critical to keep a uniform thickness over the blades, to achieve the same detection efficiency independently of where in the detector neutrons are absorbed.

In Fig. 1(b), the number of layers is simulated, while the film thickness is assumed to be $1 \mu \mathrm{m}$. It can be seen that the conversion efficiency is close to $100 \%$ when using more than 50 absorbing layers. With 50 layers, even the escape efficiency is approaching its maximum, which is about $71 \%$. Unfortunately, when manufacturing a detector every additional layer makes it more complicated and more expensive. For the discussion here, we have decided to use a maximum of 30 layers, which is a compromise that lowers the number of layers by $40 \%$, but keeps the escape efficiency above $67 \%$.

Figure 1(c) shows how the conversion and escape efficiency are affected by the wavelength of the incoming neutrons, when assuming 30 layers of ${ }^{10} \mathrm{~B}_{4} \mathrm{C}$, with a thickness of $1 \mu \mathrm{m}$ each. Typical wavelengths, like $4.5 \AA$ at the ILL IN5, would give an escape efficiency of $67 \%$, while wavelengths 
below 3-4 § lead to a drastically reduced response. From these results, it is clear that small changes in the wavelength (especially to higher values) do not affect the efficiency of the detector to a large extent, but for an optimized detector operating at a very different wavelength, the number of layers and their respective thickness need to be adjusted accordingly.

In a large-scale production of coated blades, where the price and time per coated layer plays an important role, the allowed amount of impurities in the films will be critical. The simulations in Fig. 1(d) use film thicknesses of $1 \mu \mathrm{m}$ and 30 layers, and show how much an addition of 10 at. \% of the common contaminants $\mathrm{H}, \mathrm{C}, \mathrm{N}, \mathrm{O}$, and Ar would influence the escape efficiency at a wavelength of $4.5 \AA$, respectively. All impurities lower the efficiency in comparison to pure ${ }^{10} \mathrm{~B}_{4} \mathrm{C}$, although the effect of the lighter elements is significantly smaller. The simulations clearly show how important it is to keep the amount of contaminants in the films as low as possible if the neutron detection efficiency is to be retained at an acceptable level. Therefore, all possible ways to lower the amount of impurities in the experimental work have to be considered.

\section{B. Experiments}

Deposition experiments were performed with the aim to optimize the neutron detection efficiency, following the results from the simulations. Special focus was put into increasing the film adhesion, lowering the amount of impurities, and controlling the thickness and its uniformity.

All deposition experiments yield films with a dense, columnar structure, and smooth surface, as can be seen in a typical cross sectional SEM image of a $800 \mathrm{~nm}$ thick ${ }^{\text {nat }} \mathrm{B}_{4} \mathrm{C}$ thin film deposited onto $\mathrm{Si}$ at $100^{\circ} \mathrm{C}$, in Fig. 2(a). The film has a good adhesion, as shown below, and a uniform thickness within the studied area. Changing the substrate temperature during deposition does not remarkably change the structure, as can be seen in Fig. 2(b), where a ${ }^{\text {nat }} \mathrm{B}_{4} \mathrm{C}$ thin film deposited at $400{ }^{\circ} \mathrm{C}$ is shown. The thickness variation in the $400^{\circ} \mathrm{C}$ sample can be explained by a densification at increased temperatures (described below).

In Fig. 3, we compare adhesions with densities for films grown with different deposition rates (indicated by the applied magnetron powers) and at different growth temperatures. The figure shows an increase in density both with increasing deposition rate and with increasing deposition temperature. The lowest measured density of $1.89 \mathrm{~g} / \mathrm{cm}^{3}$, for a thin film deposited with the lowest deposition rate and at the lowest temperature, corresponds to $75 \%$ of the nominal $\mathrm{B}_{4} \mathrm{C}$ density of $2.52 \mathrm{~g} / \mathrm{cm}^{3}$. With this density, the optimal film thickness would, according to the simulations, have to be $1067 \mathrm{~nm}$, which is at the thickness limit for well-adhering films.

The adhesion was determined by a tape test performed on films deposited onto $\mathrm{Al}$, with $3 \mathrm{M}$ Scotch Brand Tape (393) and quantified with an adhesion scale from 0 (the thin film spalls off completely) to 5 (the thin film does not spall off at all). Like in previous reports, ${ }^{15}$ we observed (not shown) that films thicker than $\sim 1 \mu$ m have a tendency to

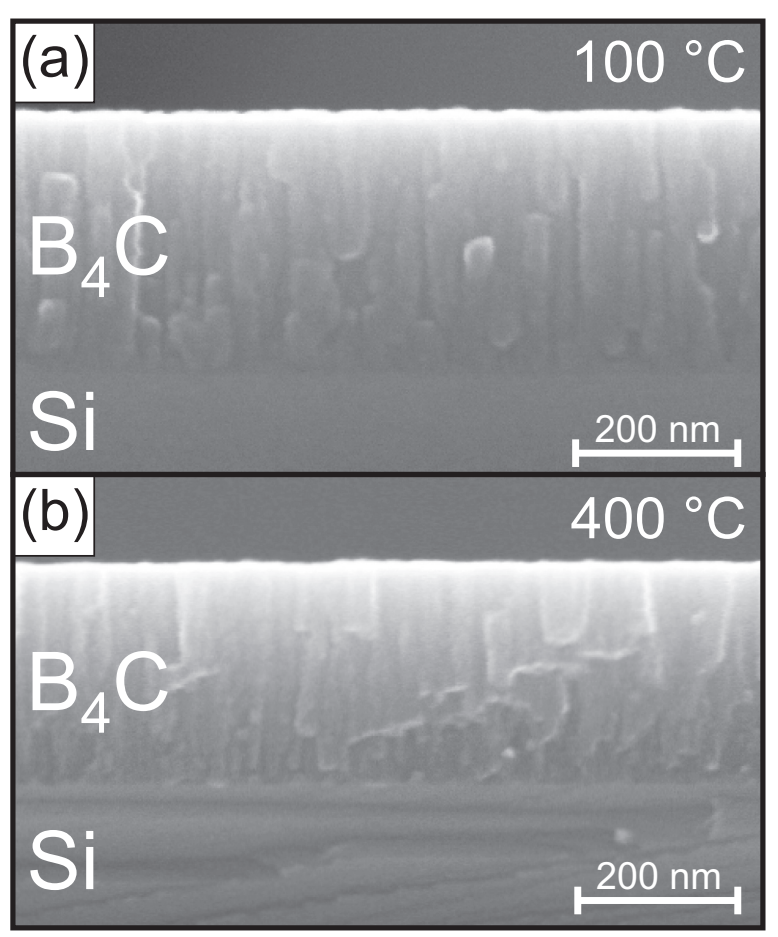

FIG. 2. Typical cross-sectional SEM images, showing ${ }^{\text {nat }} \mathrm{B}_{4} \mathrm{C}$ thin films deposited onto $\mathrm{Si}$ at a substrate temperature of (a) $100^{\circ} \mathrm{C}$ and (b) $400{ }^{\circ} \mathrm{C}$.

spall off the substrate when not heating the substrate and keeping the deposition rate low. Fig. 3 reveals that the thin films deposited at $100^{\circ} \mathrm{C}$ have a significantly worse adhesion to the substrate, than the films at $300^{\circ} \mathrm{C}$ or even $400^{\circ} \mathrm{C}$. At $100^{\circ} \mathrm{C}$, even the deposition rate seems to play a role, with higher deposition rate yielding better adhesion.

A comparison between the density and the adhesion indicates that the adhesion can directly be related to the density of the film. Therefore, one way to solve the adhesion problem is to increase the substrate temperature. As alloyed Al may have a considerably lowered melting temperature, deposition temperatures beyond $500{ }^{\circ} \mathrm{C}$ were avoided. Furthermore, the higher the temperature is, the larger the risk of having diffusion of substrate species into the film. Our experiments show

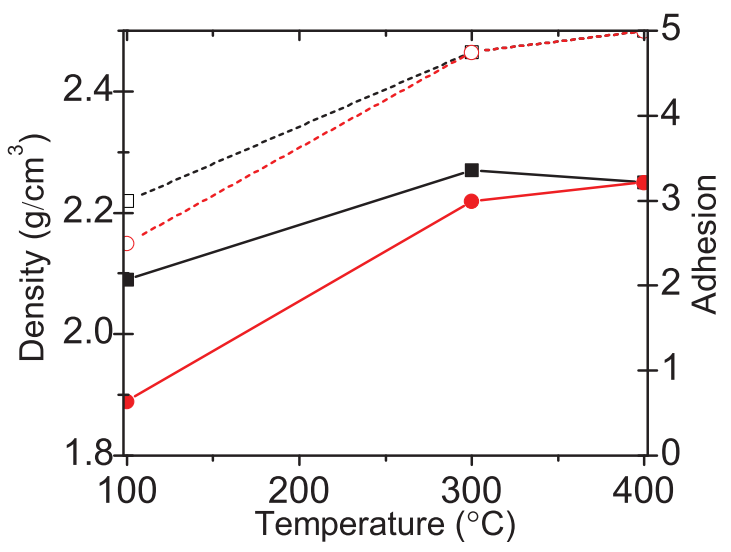

FIG. 3. Density (left) of thin films deposited with $1 \times 1500 \mathrm{~W}$ (red solid curve with dots) and $1 \times 4000 \mathrm{~W}$ (black solid curve with squares), and adhesion (right) for $1 \times 1500 \mathrm{~W}$ (red dotted curve with dots) and $1 \times 4000 \mathrm{~W}$ (black dotted curve with squares) deposited at temperatures between 100 and $400{ }^{\circ} \mathrm{C}$. 
that depositions at higher temperatures lead to a clearly better adhesion. For instance, at $400^{\circ} \mathrm{C}$, films can be grown with good adhesion to thicknesses up to above $3 \mu \mathrm{m}$. In addition, density measurements show that depositions at $400^{\circ} \mathrm{C}$ increase the film density to $2.25 \mathrm{~g} / \mathrm{cm}^{3}$ (90\% of the bulk value), corresponding to an optimal film thickness of $896 \mathrm{~nm}$, which with a margin is within the possible limits. No tendency for inter-diffusion between film and substrate can be identified with ToF-ERDA or cross-sectional SEM, despite the relatively high temperature, which also attests to the high film density achieved.

Compositional analysis was performed with ToF-ERDA. The main advantage with this technique for the present study is that it allows for quantification of the relative amounts of all light elements and their isotopes. In addition, their elemental depth-distribution can be seen throughout a thickness of $\sim 500 \mathrm{~nm}$, which enables studies of depth uniformity and inter-diffusion.

For the intended detector design, it is necessary to have the blades coated on both sides. Rotating the blades in a deposition chamber instead of having them fixed in front of the sputtering target is a cost effective way to coat them uniformly on two sides. A drawback is that sample rotation significantly reduces the deposition rate and in the applied deposition chamber the rate with rotation is only $\sim 20 \%$ of the fixed sample case, under otherwise identical deposition conditions. The ToF-ERDA spectra in Fig. 4 show a typical example of what happens when rotating the samples or not during sputtering from one ${ }^{\text {nat }} \mathrm{B}_{4} \mathrm{C}$ target operated at $1500 \mathrm{~W}$ and a substrate temperature of $100^{\circ} \mathrm{C}$. It can clearly be seen that the amount of impurities is closely related to the deposition rate and that especially the amounts of $\mathrm{H}$ and $\mathrm{O}$ are affected. The reason why also the B-content changes, is that ToF-ERDA yields relative amounts of each element, which

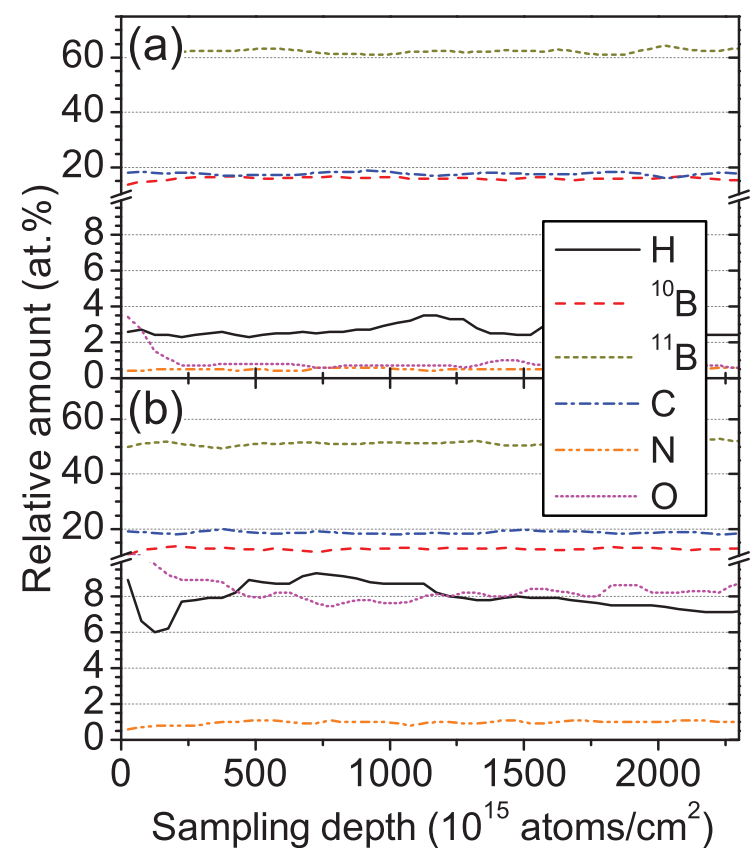

FIG. 4. ToF-ERDA depth profile from a ${ }^{\text {nat }} \mathrm{B}_{4} \mathrm{C}$ thin film deposited onto an Al-blade from one sputtering target with (a) the blade positioned in front of the target and (b) with the blade rotating for 2-sided coating. means that more impurities give relatively less B. Independent of deposition parameters, and in general for all measured samples, the layers exhibit a uniform elemental distribution throughout the film depth. The only element that has a larger spread in the measurements is $\mathrm{H}$, which is explained by poorer statistics compared to other elements due to a lower scattering cross section.

Another factor that is equal for all deposition conditions is the ${ }^{10} \mathrm{~B}$ to ${ }^{11} \mathrm{~B}$ ratio, which always is close to the naturally occurring ratio of $1: 4$ in the ${ }^{\text {nat }} \mathrm{B}_{4} \mathrm{C}$ target. Using the sputtering target containing ${ }^{10} \mathrm{~B}$ enriched ${ }^{10} \mathrm{~B}_{4} \mathrm{C}$, would consequently yield an amount of ${ }^{10} \mathrm{~B}$, corresponding to the sum of ${ }^{10} \mathrm{~B}$ and ${ }^{11} \mathrm{~B}$ in the present case.

Slightly increasing amounts of impurities towards the film surface, as seen in the depth profiles in Fig. 4, indicate that the post-growth in-diffusion is very limited and confirms that the resulting film structure is relatively dense. A dense structure is desirable, because it is expected to be more resistant against oxidation, which should lengthen the lifetime of such a detector.

In an attempt to lower the amount of incorporated impurities when using sample rotation, the substrate temperature was varied from 100 to $400{ }^{\circ} \mathrm{C}$, and the number of ${ }^{\text {nat }} \mathrm{B}_{4} \mathrm{C}$ targets and the applied power on each target were increased. The results can be seen in Fig. 5, where the sum of the impurities $\mathrm{H}, \mathrm{O}$, and $\mathrm{N}$ are shown in (a) and the relative amounts of ${ }^{10} \mathrm{~B}$ are shown in (b).

Independent of the number of targets and applied powers, it can be seen in Fig. 5 that the amount of impurities decreases significantly when increasing the substrate temperature, directly leading to an increase in the ${ }^{\text {nat }} \mathrm{B}_{4} \mathrm{C}$ content, and hence also the ${ }^{10} \mathrm{~B}$ content. The most rapid increase in ${ }^{10} \mathrm{~B}$ with increased temperature is observed for the case where one target is operated at the lowest applied magnetron

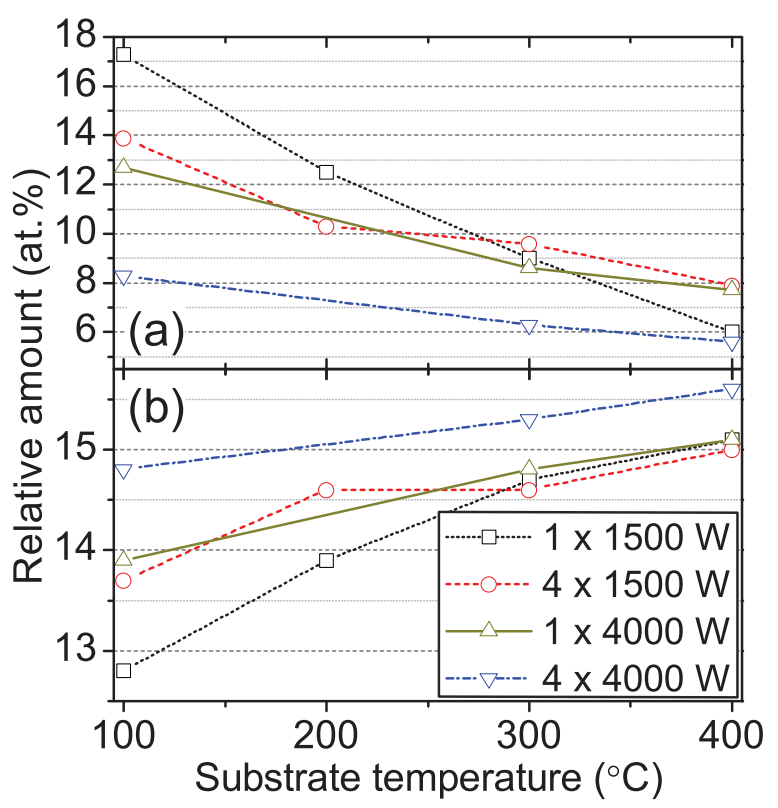

FIG. 5. Relative amounts of (a) the sum of $\mathrm{H}, \mathrm{O}$, and $\mathrm{N}$ and (b) ${ }^{10} \mathrm{~B}$ in ${ }^{\text {nat }} \mathrm{B}_{4} \mathrm{C}$ thin films, at different temperatures for one or four sputtering targets operated at magnetron powers of 1500 or $4000 \mathrm{~W}$. 
power, corresponding to the lowest deposition rate. This result indicates that the impurities present at the growing surface form volatile compounds, which are subjected to thermally stimulated desorption rather than being incorporated in the film. An increase from 12.8 to 15.1 at. $\%$ in ${ }^{10} \mathrm{~B}$ content, as is the case for a thin film with ${ }^{\text {nat }} \mathrm{B}_{4} \mathrm{C}$, would correspond to an increase from 64 to 75.5 at. $\%$ of ${ }^{10} \mathrm{~B}$ in a ${ }^{10} \mathrm{~B}_{4} \mathrm{C}$ film. Thus, the resulting efficiency of a ${ }^{10} \mathrm{~B}_{4} \mathrm{C}$ based neutron detector will be very sensitive to the deposition temperature of the films.

Increasing the number of magnetrons, but keeping the applied powers on each magnetron, results in a higher amount of ${ }^{10} \mathrm{~B}$ at low temperatures than in the previous case, while this desirable effect is absent for temperatures above $300^{\circ} \mathrm{C}$. A very similar effect can be seen for the case when only one target is used, but the applied power is raised to $4000 \mathrm{~W}$.

When increasing the deposition rate by close to a factor of four, meaning that four targets are operated at $4000 \mathrm{~W}$ each, a clear difference from the previous cases is observed. Already at a substrate temperature of $100{ }^{\circ} \mathrm{C}$, the total amount of impurities is almost as low as 8 at. \%, and the amount of ${ }^{10} \mathrm{~B}$ approaches 15 at. \%. The lowest amount of impurities (5.6 at. \%) is seen for films grown with four targets at $4000 \mathrm{~W}$ each and a substrate temperature of $400{ }^{\circ} \mathrm{C}$. The amount of ${ }^{10} \mathrm{~B}$ is then 15.6 at. $\%$, and the total amount of $\mathrm{B}$ is 77 at. \%. These results therefore suggest that a ${ }^{10} \mathrm{~B}_{4} \mathrm{C}$ thin film will contain as much as 77 at. $\%$ of ${ }^{10} \mathrm{~B}$ under the applied deposition conditions.

A decreasing amount of $\mathrm{C}$ in the films is seen for increasing deposition rates and increasing temperatures (not shown), following the trend for the other mentioned impurities. The lowest amount of $\mathrm{C}$ is seen for $4 \times 4000 \mathrm{~W}$ and $400{ }^{\circ} \mathrm{C}$, and is 17.4 at. \%. Surprisingly, this is lower than the expected ( $\sim 19$ at. \%) when sputtering from $\mathrm{a}^{\text {nat }} \mathrm{B}_{4} \mathrm{C}$ source and taking the 77 at. $\%$ of B and 5.6 at. \% of other impurities into account, but such a carbon loss could be explained by chemical sputtering and pumping of gaseous species reacted with residual gas. ${ }^{25}$

When keeping in mind that these films were made in a non-optimized industrial deposition system, which also had to be fully ventilated between each deposition run, there is a clear potential to raise the effective amount of the neutronabsorbing element even more by improving the vacuum conditions. On the other hand, it is economically not possible to implement a full-scale process under ultra clean laboratory conditions hence a compromise is needed.

Another challenge is the thickness uniformity over large areas when up-scaling the process. This is further complicated, since the price for ${ }^{10} \mathrm{~B}_{4} \mathrm{C}$ will be an essential part of the cost for a full-scale detector and loss of material needs to be reduced. Maximizing the area of thin film per gram of used target material and achieving as good uniformity as possible over large substrates will be a non-trivial geometric problem to solve. This is demonstrated in the following experiment.

The lower part of Fig. 6 presents a sketch of the $50 \mathrm{~cm}$ long sputtering target in a typical CC800/9 deposition system. Si-monitor substrates were mounted at different positions in relation to the sputtering targets. The substrates were

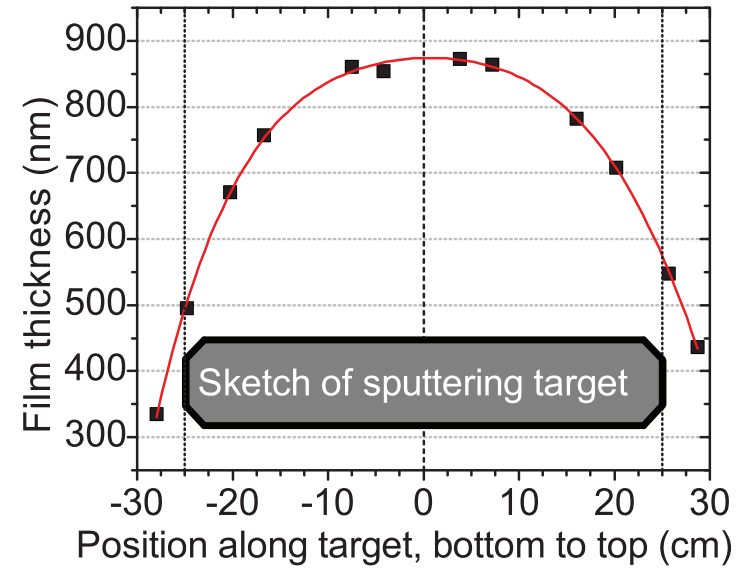

FIG. 6. Measured film thicknesses on Si-substrates (black squares) mounted on different positions along a sputtering target (sketch insert) mounted in a CC800/9 deposition system, together with a polynomial fit of the film thickness (red curve).

coated from 4 targets while rotating. Afterwards, the thicknesses of the films were measured with cross-sectional SEM and the result in relation to the position along the target can be seen in Fig. 6. A thickness variation from $\sim 500 \mathrm{~nm}$ for samples positioned at the edge of the sputtering target to $850 \mathrm{~nm}$ for samples in the target center, can be seen. This shows that to deposit blades with a length of $\sim 50 \mathrm{~cm}$ will lead to a thickness variation of $\sim 60 \%$, with the applied setup. An application like the suggested neutron detector needs to have a similar sensitivity everywhere, which is not possible to achieve with non-uniform thin films. Therefore, it is a great challenges to make large areas of films with uniform thickness, whereas little material as possible is wasted.

To get an initial indication for if the thin $\mathrm{B}_{4} \mathrm{C}$ films can be used to absorb neutrons in the way it was intended, neutron radiography measurements were performed on the above-described ${ }^{\text {nat }} \mathrm{B}_{4} \mathrm{C}$ thin films. In Fig. $7(\mathrm{a})$, the graph shows the measured absorption for ${ }^{\text {nat }} \mathrm{B}_{4} \mathrm{C}$ films with different thicknesses. The two curves show results from films deposited from 1 and 4 targets, each operated at magnetron powers of $1500 \mathrm{~W}$, respectively. By increasing the deposition rate, the amount of impurities is lowered while the relative amount of ${ }^{10} \mathrm{~B}$ increases, as was seen from the red and black data points at a substrate temperature of $100^{\circ} \mathrm{C}$ in Fig. 5 . The increasing absorption for both increased film thickness and increased amount of ${ }^{10} \mathrm{~B}$ agrees well with the conversion efficiency results from the simulations in Fig. 1, even though the measurements were performed on 2 converting layers of ${ }^{\text {nat }} \mathrm{B}_{4} \mathrm{C}$ (2-side coated blades) and the simulations were done for 30 layers of ${ }^{10} \mathrm{~B}_{4} \mathrm{C}$. A relative increase in the absorption by $\sim 50 \%$ for layer thicknesses of $\sim 1 \mu \mathrm{m}$, when decreasing the amount of impurities from 17.2 to 14 at. \%, once again shows how essential it is to minimize the amounts of impurities in the films.

Neutron absorption measurements were also performed on thin films, which were deposited from $4{ }^{\text {nat }} \mathrm{B}_{4} \mathrm{C}$ targets operated at $1500 \mathrm{~W}$ each, with the same deposition time, but at different substrate temperatures. The film composition is given by the red dashed curve in Fig. 5, and the absorption results are shown in Fig. 7(b). The fraction of ${ }^{10} \mathrm{~B}$ increases 

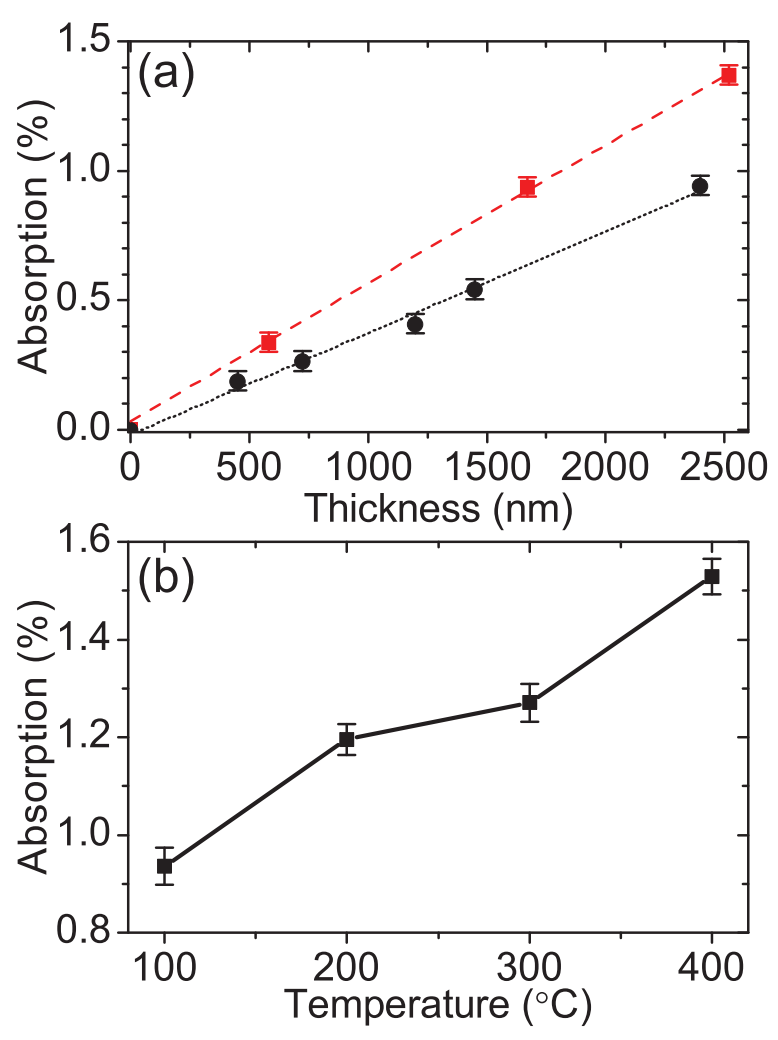

FIG. 7. Neutron absorption data, recorded for (a) $1 \times 1500 \mathrm{~W}$ (red squares) with linear fit (red dashed line) and $4 \times 1500 \mathrm{~W}$ (black dots) with linear fit (black dotted line) depending on film thickness, and (b) $4 \times 1500 \mathrm{~W}$ for varied temperatures.

by $9.5 \%$ when increasing the temperature from $100{ }^{\circ} \mathrm{C}$ to $400{ }^{\circ} \mathrm{C}$, while the absorption increases by roughly $63.2 \%$, which is an unexpectedly large amount.

Fig. 7 shows that the absorption measurements are very consistent with both simulations and compositional analyses of as-deposited thin films. Therefore, it is reasonable to assume that the highest absorbing thin films and the most suited for neutron detection, among the ones in this study, would be the ones that are deposited with the highest deposition rate and at the highest possible temperature.

A boron-10 enriched ${ }^{10} \mathrm{~B}_{4} \mathrm{C}$ sputtering target was used to deposit thin films of ${ }^{10} \mathrm{~B}_{4} \mathrm{C}$ at a substrate temperature of $400{ }^{\circ} \mathrm{C}$ and a power of $4000 \mathrm{~W}$. To maximize the amount of ${ }^{10} \mathrm{~B}$ in the film, additional cleaning procedures were carried out in the deposition chamber prior to deposition. During deposition, full pumping speed was also kept and the flow of Ar was adjusted accordingly. The compositional analysis performed with ToF-ERDA in Fig. 8 shows that these optimized deposition conditions yield thin films with almost 80 at. $\%$ of ${ }^{10} \mathrm{~B}$, with uniform elemental distribution throughout the film. The total amount of impurities $(\mathrm{H}+\mathrm{O}+\mathrm{N})$ is only 1.2 at. $\%$ and the 2.4 at. $\%$ of ${ }^{11} \mathrm{~B}$ corresponds to a boron-10 enrichment of $97 \%$ in the target. Using more than one ${ }^{10} \mathrm{~B}_{4} \mathrm{C}$ sputtering target might lower the amount of impurities even more, according to Fig. 5, and would possibly rise the amount of ${ }^{10} \mathrm{~B}$ to above 80 at. $\%$.

Cross-sectional SEM and density measurements indicate that the structure and properties of ${ }^{10} \mathrm{~B}_{4} \mathrm{C}$ are very similar to what was achieved for ${ }^{\text {nat }} \mathrm{B}_{4} \mathrm{C}$ in the study above and are

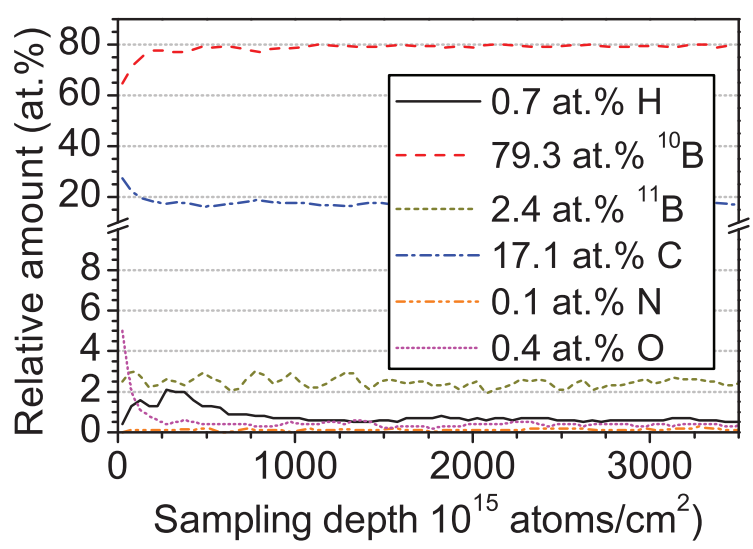

FIG. 8. ToF-ERDA depth profile from a ${ }^{10} \mathrm{~B}_{4} \mathrm{C}$ thin film deposited onto $\mathrm{Si}$ from a ${ }^{10} \mathrm{~B}_{4} \mathrm{C}$ sputtering target.

therefore not shown here. All process conditions for sputtering from the ${ }^{\text {nat }} \mathrm{B}_{4} \mathrm{C}$ and ${ }^{10} \mathrm{~B}_{4} \mathrm{C}$ targets were also chemically identical and found to be physically similar in terms of target voltage and deposition rate. This justifies the use of a ${ }^{\text {nat }} \mathrm{B}_{4} \mathrm{C}$ sputter target for those experiments that did not require high amounts of ${ }^{10} \mathrm{~B}$.

To prove the suitability of the process to coat large areas, $6.3 \mathrm{~m}^{2}$ of $1 \mu \mathrm{m}$ thick ${ }^{10} \mathrm{~B}_{4} \mathrm{C}$ was deposited on $\mathrm{Al}$ blades in 24 separate deposition runs, for the purpose of a larger prototype detector. ${ }^{8}$ ToF-ERDA and cross-sectional SEM measurements were performed for a selection of the runs and show no systematic variations between runs. The amounts of ${ }^{10} \mathrm{~B}$ and impurity levels are equivalent to the ones seen in Fig. 8. The detector efficiency was close to expectations $^{8}$ and varies with $\pm 1 \%$, which is well within tolerances for variations. ${ }^{26}$ The results prove that a consistent high quality of the thin films was achieved throughout the deposition runs.

\section{CONCLUSIONS}

Through a combination of simulations and experiments, we present the most important aspects for optimal ${ }^{10} \mathrm{~B}_{4} \mathrm{C}$ thin films on Al-blades intended for a new generation large area neutron detector, as potential replacement for the ${ }^{3} \mathrm{He}$ based ones used today. Minimized amounts of impurities and films with good adhesion are essential for the neutron absorption performance. The results show that high quality thin films are obtained using increased substrate temperatures and high deposition rates. ${ }^{\text {nat }} \mathrm{B}_{4} \mathrm{C}$ thin films that are deposited at $400{ }^{\circ} \mathrm{C}$ and a total applied sputtering power of $16 \mathrm{~kW}$ can be grown to thicknesses exceeding $3 \mu \mathrm{m}$ and have a density close to bulk $\mathrm{B}_{4} \mathrm{C}$. We also illustrate that a uniform film thickness over large areas is essential, and show how the film thickness and optimal number of layers depend on the neutron wavelength for maximized neutron detection efficiency. $6.3 \mathrm{~m}^{2}$ of $1 \mu \mathrm{m}$ thick ${ }^{10} \mathrm{~B}_{4} \mathrm{C}$ thin films coated on Al-blades yield a prototype detector efficiency variation of only $\pm 1 \%$. These films contain almost 80 at. $\%$ of ${ }^{10} \mathrm{~B}$. Based on our findings, we conclude that it is feasible to produce 2-sided ${ }^{10} \mathrm{~B}_{4} \mathrm{C}$ coatings on an industrial scale at a competitive price, 
and that it is a promising candidate as a neutron conversion layer in ${ }^{10} \mathrm{~B}$-based new generation large area detectors. ${ }^{27}$

\section{ACKNOWLEDGMENTS}

This work was carried out as a part of the collaboration between the ILL, ESS, and Linköping University on developing ${ }^{10} \mathrm{~B}$ thin film neutron detectors, within the context of the International Collaboration on the development of Neutron Detectors (www.icnd.org). The authors would like to thank the management of the ILL, ESS, and Thin Film Division at Linköping University for their support and encouragement, and the technical groups at the ILL and Linköping University whose expertise and ingenuity are invaluable contribution. The authors would also like to acknowledge the Tandem Laboratory at Uppsala University for giving access to their ion beam facilities, and Karl Zeitelhack at the Technical University of Munich for his contribution through discussions. L.H. acknowledges the European Research Council Advanced Grant and the Swedish Government Strategic Research Area Grant in Materials Science.

\footnotetext{
${ }^{1}$ A. Cho, Science 326, 778 (2009).

${ }^{2}$ D. A. Shea and D. Morgan, Congressional Research Service Report No. R41419, 2010.

${ }^{3}$ D. Kramer, Phys. Today 64, 20 (2011).

${ }^{4}$ See http://www.icnd.org for International collaboration on the development of neutron detectors

${ }^{5}$ T. M. Persons and G. Aloise, United States Government Accountability Office, Report No. GAO-11-753, 2011.

${ }^{6} \mathrm{~J}$. Ollivier, H. Mutka, and L. Didier, in The New Cold Neutron Time-ofFlight Spectrometer IN5, Neutron News 21:2, 22 (2010).

${ }^{7}$ ILL patent application FR\#10/51502 (2 March 2010).

${ }^{8}$ K. Andersen, T. Bigault, J. Birch, J.-C. Buffet, J. Correa, P. van Esch, B. Guerard, R. Hall-Wilton, L. Hultman, C. Höglund, J. Jensen, A. Khaplanov,
}

O. Kirstein, F. Piscitelli, and C. Vettier, Nucl. Instrum. Methods Phys. Res. A (submitted).

${ }^{9}$ O. Knotek, E. Lungscheider, and C. W. Siry, Surf. Coat. Technol. 91, 167 (1997).

${ }^{10}$ S. Ulrich, T. Theel, J. Schwan, and H. Ehrhardt, Surf. Coat. Technol. 97, 45 (1997).

${ }^{11}$ E. Pascual, E. Martinez, J. Esteve, and A. Lousa, Diamond Relat. Mater. 8, 402 (1999).

${ }^{12}$ M. A. McKernan, Surf. Coat. Technol. 49, 411 (1991).

${ }^{13}$ M. U. Guruz, V. P. Dravid, and Y. W. Chung, Thin Solid Films 414, 129 (2002).

${ }^{14}$ A. Lousa, E. Martinez, J. Esteve, and E. Pascual, Thin Solid Films 355, 210 (1999).

${ }^{15}$ T. Tavsanoglu, O. Yucel, O. Addemir, and M. Jeandin, in TMS Annual Meeting (Wiley, 2008), Vol. 1, p. 279.

${ }^{16}$ M. J. Zhou, S. F. Wong, C. W. Ong, and Q. Li, Thin Solid Films 516, 336 (2007).

${ }^{17}$ S. Ulrich, H. Ehrhardt, J. Schwan, R. Samlenski, and R. Brenn, Diamond. Relat. Mater. 7, 835 (1998)

${ }^{18}$ M.-L. Wu, J. D. Kiely, T. Klemmer, Y.-T. Hsia, and K. Howard, Thin Solid Films 449, 120 (2004)

${ }^{19} \mathrm{M}$. S. Janson, "CONTES conversion of time-energy spectra-A program for ERDA data analysis," Internal Report, Uppsala University, 2004.

${ }^{20}$ M. Klein, "Experimente zur Quantenmechanik mit ultrakalten Neutronen und Entwicklung eines neuen Detektors zum ortsaufgelösten Nachweis von thermischen Neutronen auf großen Flächen," Ph.D. dissertation (University of Heidelberg, 2000)

${ }^{21}$ Z. Wang and C. L. Morris, Nucl. Instrum. Methods Phys. Res. A 652, 323 (2011).

${ }^{22}$ See http://www.srim.org/for SRIM-2008.

${ }^{23}$ J. Correa, B. Guérard, A. Khaplanov, F. Piscitelli, and P. Van Esch, "On the theoretical efficiency of multi-layer boron-film neutron detectors," (unpublished)

${ }^{24}$ B. Guérard in D16 A new detector for D16: Bidim26, ILL News 12/2002 (2002).

${ }^{25}$ M. P. Johansson, L. Hultman, S. Daaud, K. Bewilogua, H. Lüthje, A. Schütze, S. Kouptsidis, and G. S. A. M. Theunissen, Thin Solid Films 287, 193 (1996).

${ }^{26}$ A. Khaplanov, K. Andersen, T. Bigault, J. Birch, J.-C. Buffet, J. Correa, P. van Esch, B. Guerard, R. Hall-Wilton, L. Hultman, C. Höglund, J. Jensen, A. Khaplanov, O. Kirstein, F. Piscitelli, and C. Vettier, Proceedings of ICANS XX, Bariloche, Rio Negro, Argentina, March, 2012.

${ }^{27}$ PCT application number PCT/SE2011/050891 (30 June 2011). 